\title{
Exploring the Use of Herbal Treatments During Pregnancy Among Saudi Women An application of the knowledge-attitude-practice model
}

Fatmah Almoayad, ${ }^{1}$ Insherah A. Assiri, ${ }^{1}$ Haifa F. Almarshoud, ${ }^{1}$ Atheer M. Safhi, ${ }^{1}$ Hend M. Altahan, ${ }^{1}$ Nada Benajiba ${ }^{2}$

\begin{abstract}
Objectives: Herbal treatments are commonly used by Saudi women during pregnancy. However, the inappropriate use of some herbs can have side-effects for both the mother and the fetus. Thus, a comprehensive understanding of their use during pregnancy is crucial. This study aimed to explore the use of herbal treatments by Saudi women during pregnancy using the knowledge-attitude-practice model. Methods: This cross-sectional study was conducted from September 2019 and April 2020 in Riyadh, Saudi Arabia, on a convenience sample using an online Arabic-language questionnaire. Saudi women aged between 18-58 years who were pregnant or had been pregnant and were living in the Riyadh were included. Results: A total of 400 individuals participated in this study. All participants lacked knowledge about the side-effects of herbal treatment but $63 \%$ knew about unsafe herbs in general. Most participants (66\%) had a neutral attitude towards herbal treatments. Almost half of the participants (48\%) did not use herbs during pregnancy and a similar number (47\%) sometimes used herbal treatments during pregnancy. There was a significant positive correlation between attitude and practice and a negative correlation between knowledge and attitude as well as between knowledge and practice $(P<0.0001$ each). Conclusion: While the participants' knowledge were generally poor, their attitudes and practices regarding the use of herbal treatments during pregnancy were good. It is recommended that more efforts be made by healthcare providers to target attitudes towards herbal treatments by providing accurate knowledge and reinforcing healthy practices among Saudi women.
\end{abstract}

Keywords: Herbal Medicine; Pregnancy; Health Knowledge, Attitudes, Practice ; Saudi Arabia.

\begin{abstract}
ADVANCES IN KNOWLEDGE
This study found that efforts are needed to enhance Saudi women's knowledge of the risks of using herbal treatments during pregnancy. Improving knowledge of the specific side-effects of individual, commonly used herbal treatments would strengthen attitudes and promote healthy practices regarding the use of herbal treatments during pregnancy.

Applications to Patient Care

The findings of this study provided scientific evidence of the need for support from healthcare providers for Saudi women regarding the use of herbal treatments, even before conception.

Furthermore, it is important to identify the specific side-effects of herbal treatments during pregnancy.
\end{abstract}

$\mathrm{H}$ ERBAL TREATMENTS ARE COMMON WORLDwide and particularly in Arab countries, as they are integrated into Arab culture. ${ }^{1,2}$ Pregnant women use herbs for multiple reasons, such as to treat nausea and vomiting, and are generally preferred to prescribed medications because herbs are perceived as a safer option. ${ }^{3}$ In Saudi Arabia, herbal treatments are traditional; they are widely available and culturally accepted as a result of being promoted by certain religious leaders. ${ }^{4}$ Almost a quarter of Saudi women use herbal treatments during pregnancy, whereas a third of these women use them during labour and almost half use herbal treatments after delivery. ${ }^{1}$ Some of the most common herbs reported to have been used during pregnancy in Saudi Arabia are ginger (Zingiber officinale), liquorice (Glycyrrhiza glabra), ginseng (Panax ginseng), clove (Syzygium aromaticum), fenugreek (Trigonella foenum-graecum), sage (Salvia officinalis), senna (Senna alexandrina), chamomile (Matricaria recutita), fennel flower seed (Nigella sativa), cinnamon (Cinnamomum verum), castor oil (Ricinus communis), myrrh (Commiphora myrrha), thyme (Thymus vulgaris), anise (Pimpinella anisum), parsley (Petroselinum crispum), turmeric (Curcuma longa) and peppermint (Mentha piperita). ${ }^{5}$ Some of these are considered potentially unsafe including liquorice, myrrh, fenugreek, castor, parsley and turmeric. However, it is safe to use others when combined with food in small amounts. For some herbs, there is a lack of evidence about their safety and some have been reported as safe for use by pregnant women.

Studies have shown that some herbs are associated with miscarriages, stillbirths and preterm delivery including liquorice, myrrh, fenugreek, parsley, castor oil and thyme. ${ }^{6-11}$ Additionally, some herbs have 
been found to harm the fetus; fenugreek can cause fetal malformation, teratogens and congenital defects and parsley oil can cause haemoglobin anomalies in the foetus. ${ }^{8,9}$

In contrast, anise is safe for use during pregnancy and anise oil has proven effective in treating genital infections and reducing the risk of premature labour. ${ }^{12,13}$ There is little evidence about whether chamomile is safe for pregnant women. It is commonly used for its sedative properties to help pregnant women relax and it can aid digestion. However, it has been shown that chamomile can cause an allergic reaction in some women and may lead to a miscarriage. ${ }^{11}$ Multiple studies have confirmed that peppermint oil is useful for relieving irritable bowel syndrome and reducing nausea. ${ }^{11}$ Evidence indicates that peppermint oil is particularly effective for relieving itching. ${ }^{14}$ However, more research is required to exclude its side-effects when used during pregnancy. ${ }^{11}$ Sage has been reported to be safe for use by pregnant women after 37 weeks of gestation but high doses may lead to miscarriage; smelling sage has been shown to help pregnant women relax. Although there is no evidence that ginseng causes harm to pregnant women, current advice is that it should not be consumed in the first trimester. ${ }^{15}$ Cinnamon is a known herbal treatment for women to treat excessive menstruation and uterine haemorrhage excess stomach acid and dyspepsia and is generally considered safe for pregnant women. ${ }^{16}$ Similarly, ginger, which is used to relieve some symptoms of pregnancy, especially nausea, is safe when used in appropriate amounts (no more than $1 \mathrm{~g}$ ). ${ }^{11}$

Senna, cloves and fennel flower seeds are safe for consumption by pregnant women in food and in small amounts. ${ }^{12,17,18}$ While it is safe for pregnant women to consume turmeric in food, it may interact with other herbs and drugs that cause low blood sugar and low levels of white and red blood cells. ${ }^{19}$ Finally, the use of cloves in food tends to be safe, but there is insufficient information about the possible adverse effects of consuming cloves in large amounts during pregnancy.

Overall, while some commonly used herbs are safe for pregnant women, others either have serious side-effects or there is a lack of evidence of their safety. Therefore, promoting health during pregnancy and preventing unwanted consequences of herbal treatments is vital. Due to the risks associated with the use of some herbal treatments during pregnancy, pregnant women should be careful about which herbs are consumed/used to avoid adversely affecting themselves or the fetus. ${ }^{12}$ There is a lack of awareness in the Middle East about the risks of using herbs, which is exacerbated by cultural and social beliefs regarding their safety. ${ }^{12}$
Evidence-based interventions are needed to increase awareness of this issue and encourage healthy behaviours. In health behaviour studies, the knowledgeattitude-practice (KAP) model is used to measure what individuals in a given community know, feel and believe about a specific health problem as well as to measure health-related practices. This model is useful in understanding the mechanisms of health education and health outcomes..$^{20}$ It is well established that health education interventions play a major role in improving knowledge and attitudes. Knowledge is the result of obtaining and understanding information from different types of experiences and can be influenced by health education. ${ }^{21}$ Healthcare professionals play a central and critical role in improving healthcare for pregnant women, as they provide essential services that promote health and ensure a healthy pregnancy. Indeed, they can play an important role in correcting misinformation that influences the beliefs and attitudes of pregnant women. ${ }^{22}$ Knowledge differs from attitude, which is defined as "a psychological tendency that is expressed by evaluating a particular entity with some degree of favour or disfavour". 23 According to the KAP model, the practice of using herbal treatments during pregnancy is affected by the knowledge and attitudes of pregnant women. ${ }^{21}$ Thus, while recent literature has investigated the use of herbs during pregnancy in Saudi Arabia, the current study aimed at assessing the knowledge, attitudes and practices concerning the use of herbal treatments among Saudi women. ${ }^{1,5}$ The KAP model was used to understand and explain the impact of knowledge and attitudes on practice in order to provide appropriate recommendations and promote urgent action where needed.

\section{Methods}

This cross-sectional study was carried out between September 2019 and April 2020 in the province of Riyadh (urban and rural areas), Saudi Arabia. Data were collected using an online questionnaire distributed through social media applications, mainly WhatsApp (Facebook Inc., Menlo Park, California, USA). Saudi women aged 18-58 years who were pregnant or had been pregnant at least once during the last five years prior to the study and were living in Riyadh (rural or urban area) were included. Women who had unsuccessful pregnancies, were younger than 18 years or older than 58 years and who had last been pregnant more than five years before the study were excluded in order to reduce recall bias. A convenience sampling technique was used.

The questionnaire was composed of questions relating to herbal treatments commonly used by 
women during pregnancy in Saudi Arabia mentioned in the introduction. The questionnaire consisted of four sections. Section 1 collected socio-demographic information including age, educational level, marital status, monthly income, employment status, number of children and area of residency. It also included one question about the participants' sources of information on herbal treatments during pregnancy. Section 2 assessed the participants' knowledge of herbal treatments. This section consisted of two questions that assessed knowledge about the side-effects of each herbal treatment and herbs that should not be used during pregnancy. A score of 1 was assigned for each correct answer, and a score of 0 was assigned for each wrong answer. The maximum total knowledge score was 28 and the minimum was 0 . The cut-off point was the median score. Participants who scored more than $50 \%$ were considered to have good knowledge and those who scored less than $50 \%$ were considered to have poor knowledge. Section 3 measured the attitudes of participants towards the use of herbal treatments during pregnancy. It included four questions that used a 5-point Likert scale ranging from 1 for 'strongly disagree' to 5 for 'strongly agree. ${ }^{24}$ The maximum total score for attitude was 20 and the minimum was 4. Section 4 included six questions that evaluated the practices related to herbal treatments, in particular, whether the participant had used herbal treatments, the type of herb used, the trimester in which herbs were used, how they were used, the reasons for using them and whether they were used after receiving medical advice. For the questions on whether the participant had used herbal treatments during pregnancy and whether they had sought medical advice, a score of 1 was given for an affirmative answer. The maximum total score was 2 and the minimum was 0 .

The questionnaire was designed based on a comprehensive literature review and translated into Arabic; a backwards-forwards technique was used to ensure its validity. It was reviewed by five experts, and questions were modified accordingly. Reliability was tested using Cronbach's alpha test (0.85). Finally, the questionnaire was piloted among 20 women to identify any difficulties, ambiguities or culturally sensitive questions.

The collected data were statistically analysed using JMP, Version 15.1 (SAS Institute Inc., Cary, North Carolina, USA). Descriptive statistics were presented as frequencies and percentages. Pearson's test was used to assess correlations between KAP variables. Statistical significance was set at $P \leq 0.05$.

Ethical approval was obtained from the Institutional Review Board at Princess Nourah Bint Abdulrahman University, Riyadh, Saudi Arabia (number:
Table 1: Characteristics of the study's participants and source of information on herbal treatment use in Saudi Arabia $(\mathrm{N}=400)$

\begin{tabular}{|c|c|}
\hline Characteristic & n (\%) \\
\hline \multicolumn{2}{|l|}{ Age in years* } \\
\hline $18-25$ & $34(11)$ \\
\hline $26-33$ & $128(32)$ \\
\hline $34-41$ & $138(35)$ \\
\hline $42-49$ & $74(19)$ \\
\hline $50-57$ & $17(4)$ \\
\hline \multicolumn{2}{|l|}{ Education level } \\
\hline Illiterate & $0(0)$ \\
\hline Elementary & $10(3)$ \\
\hline Intermediate & $26(7)$ \\
\hline High school & $63(16)$ \\
\hline Bachelor's degree & $241(60)$ \\
\hline Higher education & $60(15)$ \\
\hline \multicolumn{2}{|l|}{ Marital status } \\
\hline Married & $382(96)$ \\
\hline Divorced & $13(3)$ \\
\hline Widow & $5(1)$ \\
\hline \multicolumn{2}{|c|}{ Income status in Saudi Riyal } \\
\hline$<3000$ & $27(7)$ \\
\hline 3000-5999 & $48(12)$ \\
\hline 6000-8999 & $79(20)$ \\
\hline 9000-11999 & $79(20)$ \\
\hline$\geq 12000$ & $167(42)$ \\
\hline \multicolumn{2}{|l|}{ Employment status } \\
\hline Employed & $200(50)$ \\
\hline Housewife & $180(45)$ \\
\hline Retired & $20(5)$ \\
\hline \multicolumn{2}{|l|}{ Number of children } \\
\hline One & $86(22)$ \\
\hline More than one & $314(79)$ \\
\hline \multicolumn{2}{|l|}{ Residence area } \\
\hline Urban & $348(87)$ \\
\hline Rural & $52(13)$ \\
\hline \multicolumn{2}{|l|}{ Source of information $^{\dagger}$} \\
\hline Scientific website & $76(19)$ \\
\hline Non-scientific website & $12(3)$ \\
\hline Friend & $68(17)$ \\
\hline Family & $96(24)$ \\
\hline Forums & $20(5)$ \\
\hline Traditional healers & $20(5)$ \\
\hline Social media & $64(16)$ \\
\hline Doctor & $36(9)$ \\
\hline
\end{tabular}




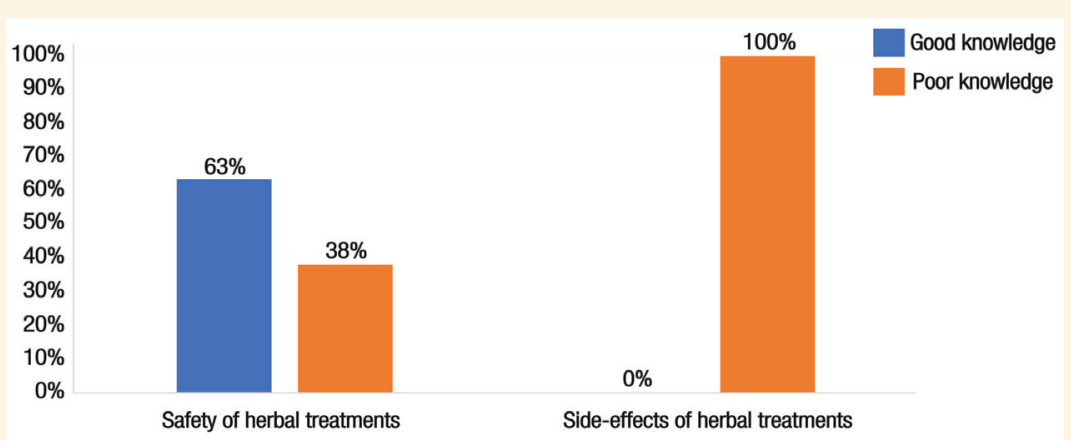

Figure 1: Distribution of participants according to their knowledge of safety and side-effects of herbal treatments $(\mathrm{N}=400)$

Table 2: Attitude of study's participants towards herbal treatment in Saudi Arabia $(\mathrm{N}=400)$

Item

I feel herbal treatments are helpful during pregnancy

I feel it is safe for pregnant women to use herbs as treatment

I feel herbal treatments are safe because they come from nature

The use of herbal treatments is socially acceptable
Strongly agree

$12(3)$

$11(3)$

$22(6)$

$59(15)$
Agree

$60(15)$

56 (14)

59 (15)

143 (36) n (\%)

Neutral

154 (39)

Disagree

112 (28)

Strongly disagree

62 (16)

118 (30)

143 (36)

72 (18)

118 (30)

134 (34)

67 (17)

$33(8)$
20-0004). Informed consent was requested on the first page of the questionnaire; consent had to be provided before taking part in the study. Furthermore, participants were recruited voluntarily and anonymity and confidentiality were maintained.

\section{Results}

A total of 400 women were included in this study. Most participants were between 26-41 years old (68\%) and most had a bachelor's degree (60\%). The majority of the participants were married (96\%). Almost half of the participants had a high income (42\%) and half were employed at the time of the study (50\%). The majority had more than one child (79\%) and most lived in an urban area of Riyadh (87\%).

Almost one quarter (24\%) of the participants obtained their information on herbal treatments from family while others obtained information from scientific websites (19\%), friends (17\%) and social media (16\%); doctors were the main source of information for $9 \%$ of the sample. Both traditional healers and online forums were reported by some as information sources (5\% each) and the least number of participants reported using non-scientific websites as their source of information (3\%) [Table 1]. Almost two-thirds of the participants (63\%) had a good level of knowledge about the unsafe use of herbal treatments in general, whereas $100 \%$ of the participants had poor information about the side-effects of specific herbs [Figure 1].

Participants tended to have a neutral attitude towards the use of herbal treatment during pregnancy. More precisely, $66 \%$ of the participants had a neutral attitude while $23 \%$ had a positive attitude and $12 \%$ had a negative attitude. Approximately half of the participants agreed that the use of herbal treatments is socially acceptable (51\%) and most (54\%) thought that using herbal treatments during pregnancy was unsafe [Table 2].

In terms of the practices of the participants regarding the use of herbal treatments, almost half used herbs 'sometimes' (47\%) and a similar number did not use herbal treatments during pregnancy (48\%). Only 5\% used herbs throughout their pregnancy. However, when participants were asked about how often they used herbal treatments without a doctor's advice, 15\% confirmed that they always used herbal treatment without advice; almost half reported doing so sometimes (48\%) and over one-third (37\%) reported not using any herbal treatments without advice.

Regarding the reasons for using herbal treatments, more than a third of the participants used herbal treatments for reasons related to pregnancy (41\%). Participants reported using herbal treatments to facilitate delivery (20\%), reduce pregnancy symptoms (18\%) and deal with other health problems (21\%). Participants consumed boiled, drenched or 
Table 3: The use of herbal treatment during different trimesters of pregnancy in Saudi Arabia $(\mathrm{N}=400)$

\begin{tabular}{|c|c|c|c|c|}
\hline Herb & $\begin{array}{c}\text { 1st } \\
\text { Trimester }\end{array}$ & $\begin{array}{c}\text { 2nd } \\
\text { Trimester }\end{array}$ & $\begin{array}{c}\text { 3rd } \\
\text { Trimester }\end{array}$ & $\begin{array}{l}\text { No } \\
\text { Use }\end{array}$ \\
\hline Liquorice & $2 \%$ & $1 \%$ & $3 \%$ & $94 \%$ \\
\hline Ginseng & $2 \%$ & $0 \%$ & $3 \%$ & $94 \%$ \\
\hline Senna & $1 \%$ & $1 \%$ & $3 \%$ & $94 \%$ \\
\hline Chamomile & $14 \%$ & $14 \%$ & $13 \%$ & $58 \%$ \\
\hline $\begin{array}{l}\text { Fennel } \\
\text { flower seed }\end{array}$ & $11 \%$ & $9 \%$ & $9 \%$ & $71 \%$ \\
\hline Clove & $6 \%$ & $4 \%$ & $7 \%$ & $83 \%$ \\
\hline Fenugreek & $4 \%$ & $4 \%$ & $9 \%$ & $84 \%$ \\
\hline Thyme & $11 \%$ & $11 \%$ & $12 \%$ & $66 \%$ \\
\hline Peppermint & $25 \%$ & $22 \%$ & $23 \%$ & $30 \%$ \\
\hline Sage & $8 \%$ & $7 \%$ & $10 \%$ & $76 \%$ \\
\hline Cinnamon & $4 \%$ & $5 \%$ & $22 \%$ & $69 \%$ \\
\hline Castor oil & $3 \%$ & $2 \%$ & $8 \%$ & $87 \%$ \\
\hline Myrrh & $8 \%$ & $7 \%$ & $12 \%$ & $73 \%$ \\
\hline Ginger & $21 \%$ & $16 \%$ & $19 \%$ & $44 \%$ \\
\hline Anise & $14 \%$ & $17 \%$ & $19 \%$ & $49 \%$ \\
\hline Turmeric & $8 \%$ & $9 \%$ & $9 \%$ & $74 \%$ \\
\hline Parsley & $11 \%$ & $10 \%$ & $10 \%$ & $70 \%$ \\
\hline
\end{tabular}

dried herbs $(27 \%, 24 \%$ and $3 \%$, respectively) or used a dermal preparation (7\%) or fresh herbs (5\%).

The majority of the participants avoided liquorice, ginseng, senna, castor oil, fenugreek, clove, sage, turmeric, myrrh, fennel flower seed, parsley and thyme . The participants used of peppermint, ginger, anise and chamomile used during all trimesters. Cinnamon was used most in the third trimester [Table 3].

There was a weakly significant negative correlation between knowledge and attitude $(\mathrm{r}=-0.21$; $P<0.0001)$ and a moderately significant positive correlation between attitude and practice $(r=0.50$; $P<0.0001)$. There was a weakly significant negative correlation between knowledge and practice $(r=-0.21$; $P<0.0001)$ [Table 4].

\section{Discussion}

This study aimed to explore the use of herbal treatments used by Saudi women during pregnancy via the KAP model. This research focused on the most common herbs used in Saudi Arabia as identified in the literature. ${ }^{5}$ To the best of the authors' knowledge, this study was the first to assess the three components of knowledge, attitudes and practices in relation to the use of herbal treatment during pregnancy and correlations
Table 4: Correlation between knowledge, attitude and practice of participants towards herbal treatments

$\begin{array}{lccc}\text { Variable* }^{*} & \text { Knowledge } & \text { Attitude } & \text { Practice } \\ \text { Knowledge score } & 1 & - & - \\ \text { Attitude score } & -0.21^{\dagger} & 1 & - \\ \text { Practice score } & -0.21^{\dagger} & 0.50^{\dagger} & 1 \\ & \text { *Correlation measured using Pearson's test. }{ }^{+} \mathrm{P}<0.0001 .\end{array}$

between them. Thus, it is expected that this analysis will contribute to providing specific recommendations for the promotion of healthy and safe practices regarding herbal treatments during pregnancy. The findings reported in this study indicated that $63 \%$ of the participants had a good level of knowledge about the safety of herbal treatments. However, $100 \%$ of the participants had poor knowledge when asked about the specific side-effects of each herb. This is inline with Al-Ghamdi et al's finding that Saudi women have good knowledge about the use of herbal treatments during pregnancy. ${ }^{1}$ The current study's findings also aligned with those of a study conducted in Norway, which found that Norwegian women had poor knowledge about the specific side-effects of different herbs during pregnancy. ${ }^{25}$ This could be explained by the participants' sources of information as more than half of the participants obtained their information from unreliable sources. This finding is supported by Al-Ghamdi et al's study, which found that half of their study's participants had used herbal treatments based on social advice. ${ }^{1}$

Despite the participants' poor knowledge about the side-effects of herbal treatments, both attitudes and practices were good. More than half of the participants felt that it was unsafe for pregnant women to use herbs as treatments. Congruent findings were reported by Al-Ghamdi et al., who also found that participants in their study believed that herbs were not safe for women to use during pregnancy. ${ }^{1}$ A possible explanation for these findings could be concern for the safety of the fetus and a consequent tendency to be more careful and selective about what the mother consumes.

Half of the participants disagreed with the notion that herbs were safe because they come from nature; half felt that herbs were socially accepted which could be due to Saudi tradition which encourages the use of herbal treatments. ${ }^{4}$ A study conducted in Nigeria found that participants used herbs because they came from natural sources and were socially accepted. ${ }^{26}$

In terms of practice, almost half of the participants did not use herbs as treatments during pregnancy; of those who did use them, more than half took them orally. Similarly, a study conducted in 
Palestine reported that more than half of the study's participants did not use herbs during pregnancy and of those who did take them, most took them orally. ${ }^{27}$ However, these findings contradicted those of a previous study conducted in Saudi Arabia where 98.5\% of the participants reported using herbal treatments. ${ }^{5}$ In contrast, Aljoher et al. reported that 33.3\% of their participants living in the city of Al-Ahsa, Saudi Arabia, had avoided natural products during pregnancy. ${ }^{28}$ A possible explanation for this could be that most participants in the current study had a high income and could afford medical drugs and thus did not need to seek herbal treatment as an affordable choice. Additionally, more than half of the participants were from a younger generation and less likely to rely on traditional treatments; this explanation is supported by $\mathrm{Al}$ Akeel et al.s findings, who found that the use of herbal treatment in Saudi Arabia is more common among those over 40 years old. ${ }^{4}$ In the current study, more participants used herbal treatment for reasons related to pregnancy than for other health problems. This finding differed from that reported by Adawi, who found that women in Palestine mostly used herbs to treat health issues other than those related to pregnancy. ${ }^{27}$

The current study found a positive correlation between attitudes and practices. In contrast, negative correlations were found between knowledge and attitudes and between knowledge and practices. This could be due to the use of the KAP model, which is based on the assumption that practice is affected by knowledge and attitude only. This model is critiqued, as it does not consider subjective norms, perceived control, behavioural beliefs or other external factors such as environmental characteristics. In addition, the study of behaviours from the perspective of individual-focused theories fails to consider emotion, which could play a significant role in the behaviour of pregnant women. ${ }^{20}$

The main limitation of this study was the use of convenience sampling. However, the use of online surveys is a useful and efficient method of data collection due to its low cost, accessibility to the study population and time efficiency. ${ }^{29}$ Another limitation of this study was the use of the KAP model to explore practice, which limited the study's ability to identify other factors affecting practice. Finally, the study represented only one region or area in Saudi Arabia. Nevertheless, Riyadh was selected as it is the capital and the most populated city in the country. Furthermore, the study focused on one region to reduce the number of variables and provide consistent analysis and precise recommendations. Further research coud be conducted in the other regions of the country.

\section{Conclusion}

This study found that while the participants' knowledge was poor, both attitudes and practices were good in relation to the use of herbal treatments during pregnancy. As this study found that knowledge was poor, specific information on the side-effects of herbal treatments during pregnancy should be provided and an emphasis should be placed on the necessity to obtain such information from appropriate sources (i.e. healthcare providers). In addition, more efforts should be made to target attitudes by providing accurate information to reinforce healthy practices among Saudi women. There is a need for comprehensive interventions to raise awareness among pregnant women about herbal treatment use; healthcare providers should play a major role in helping future mothers have a safe pregnancy throughout all three trimesters. From a research perspective, more studies on herbal treatments during pregnancy should be conducted in different regions of Saudi Arabia due to the variety of cultures in the country; these studies could draw on other behavioural theories. Finally, there is a need for studies that determine the specific doses and side-effects of herbs for both pregnant women and the fetus.

\section{CONFLICT OF INTEREST}

The authors declare no conflicts of interest.

\section{FUNDING}

This research was funded by the Deanship of Scientific Research at Princess Nourah bint Abdulrahman University through the Fast-track Research Funding Program.

\section{AUTHORS' CONTRIBUTION}

All authors substantially contributed to the design of the study. IA, HFA, AMS and HMA collected the data, performed the statistical analysis and literature review. All authors participated in the interpretation of the results and drafting the manuscript. FA and NB revised the manuscript and edited the English. All authors approved the final version of the manuscript.

\section{References}

1. Al-Ghamdi S, Aldossari K, Al-Zahrani J, Al-Shaalan F, Al-Sharif $\mathrm{S}$, Al-Khurayji $\mathrm{H}$, et al. Prevalence, knowledge and attitudes toward herbal medication use by Saudi women in the central region during pregnancy, during labor and after delivery. BMC Complement Altern Med 2017; 17:196. https://doi.org/10.1186/ s12906-017-1714-3.

2. Azaizeh H, Saad B, Khalil K, Said O. The state of the art of traditional Arab herbal medicine in the Eastern region of the Mediterranean: A review. Evid Based Complement Alternat Med 2006; 3:229-35. https://doi.org/10.1093/ecam/nel034. 
3. John LJ, Shantakumari N. Herbal medicines use during pregnancy: A review from the Middle East. Oman Med J 2015; 30:229-36. https://doi.org/10.5001/omj.2015.48.

4. Al Akeel MM, Al Ghamdi WM, Al Habib S, Koshm M, Al Otaibi F. Herbal medicines: Saudi population knowledge, attitude, and practice at a glance. J Family Med Prim Care 2018; 7:865-75. https://doi.org/10.4103/jfmpc.jfmpc_315_17.

5. Zaitoun MF, Al-Nowis ME, Alhumaidhan FY, Khalil HE. Use of herbs among pregnant women in Saudi Arabia: A cross sectional study. J Pharm Sci Res 2019; 11:2105-08.

6. Strandberg TE, Andersson S, Järvenpää AL, McKeigue PM. Preterm birth and licorice consumption during pregnancy. Am J Epidemiol 2002; 156:803-5. https://doi.org/10.1093/aje/ kwf130.

7. Al-Jaroudi D, Kaddour O, Al-Amin N. Risks of myrrh usage in pregnancy. JBRA Assist Reprod 2016; 20:257-8. https://doi. org/10.5935/1518-0557.20160050

8. Taloubi L, Rhouda H, Belahcen A, Smires N, Thimou A, Mdaghri AA. An overview of plants causing teratogenicity: Fenugreek (Trigonella foenum graecum). Int J Pharm Sci Res 2013; 4:516-19.

9. Ajmera P, Kalani S, Sharma L. Parsley-Benefits \& side effects on health. Int J Physiologt Nutr Physical Educ 2019; 4:1236-42.

10. Dugoua JJ. Herbal medicines and pregnancy. J Popul Ther Clin Pharmacol 2010; 17:e370-8.

11. Laelago T. Herbal medicine use during pregnancy: Benefits and untoward effects. From: https://www.intechopen.com/ chapters/61138 Accessed: Nov 2020.

12. Ahmed M, Hwang JH, Choi S, Han D. Safety classification of herbal medicines used among pregnant women in Asian countries: A systematic review. BMC Complement Altern Med 2017; 17:489-99. https://doi.org/10.1186/s12906-017-1995-6.

13. Sayfieva M, Rabbimova G, Muhamadiev N. Estimation of use efficiency of essential oil of anise in treatment of genital infections in pregnant women. Int J Res Med Basic Sci 2019; $5: 15-21$.

14. Akhavan Amjadi MA, Mojab F, Kamranpour SB. The effect of peppermint oil on symptomatic treatment of pruritus in pregnant women. Iran J Pharm Res 2012; 11:1073-7.

15. Seely D, Dugoua JJ, Perri D, Mills E, Koren G. Safety and efficacy of panax ginseng during pregnancy and lactation. Can J Clin Pharmacol 2008; 15:e87-94.
16. Abascal K, Yarnell E. The medicinal uses of cinnamon. Integr Med 2010; 9:28-32.

17. MedlinePlus. Senna. From: https://medlineplus.gov/druginfo/ natural/652.html\#DrugInteractions Accessed: Nov 2020.

18. Ozgoli G, Torkashvand S, Salehi Moghaddam F, Borumandnia N, Mojab F, Minooee S. Comparison of peppermint and clove essential oil aroma on pain intensity and anxiety at first stage of labor. Iran J Obstet Gynecol Infertil 2016; 19:1-11.

19. Bhowmik DC, Kumar K, Chandira M, Jayakar B. Turmeric: A herbal and traditional medicine. Arch Appl Sci Res 2009; 1:86-108.

20. Rimer BK, Brewer NT. Introduction to health behavior theories that focus on individuals. In: Glanz K, Rimer BK, Viswanath K. Health Behavior and Health Education: Theory, Research, and Practice. California: John Wiley \& Sons, 2008. Pp. 64-74.

21. Wan TTH, Rav-Marathe K, Marathe S. A systematic review of KAP-O framework for diabetes. Med Res Arch 2016; 3:1-21.

22. Humke W. [Medical care during pregnancy]. Munch Med Wochenschr 1967; 109:1925.

23. Eagly AH, Chaiken S. The advantages of an inclusive definition of attitude. Soc Cogn 2007; 25:582-602. https://doi.org/10.15 21/soco.2007.25.5.582

24. Likert R. A technique for the measurement of attitudes. Arch Psychol 1932; 22:5-55

25. Nordeng $\mathrm{H}$, Havnen GC. Impact of socio-demographic factors, knowledge and attitude on the use of herbal drugs in pregnancy. Acta Obstet Gynecol Scand 2005; 84:26-33. https://doi.org/10.1 111/j.0001-6349.2005.00648.x.

26. Fakeye TO, Adisa R, Musa IE. Attitude and use of herbal medicines among pregnant women in Nigeria. BMC Complement Altern Med 2009; 9:53. https://doi.org/10.1186/1472-6882-9-53.

27. Adawi DH. Prevalence and Predictors of Herb Use during Pregnancy (A study at Rafidia Governmental Hospital/ Palestine). Master's thesis, 2012, An-Najah National University, Nablus. P. 107

28. Aljoher AM, Alsaeed MA, AlKhlfan MA, Almethen AW, Almukhaitah MA, Zareen $\mathrm{H}$, et al. Pregnant women risk perception of medications and natural products use during pregnancy in Alahsa, Saudi Arabia. Egypt J Hosp Med 2018; 70:13-20. https://doi.org/10.12816/0042956.

29. Lefever S, Dal M, Matthíasdóttir A. Online data collection in academic research: Advantages and limitations. Br J Educ Technol 2007; 38:574-82. https://doi.org/10.1111/j.1467-8535.2 006.00638.x 